Check for updates

The BMJ

Cite this as: BMJ 2022;376:013 http://dx.doi.org/10.1136/bmi.013 Published: 6 January 2022

\title{
Address staffing crisis to tackle waiting list backlog, say MPs
}

\section{Elisabeth Mahase}

Tackling the backlog caused by the covid-19 pandemic is a "major and unquantifiable challenge" that will rely largely on effective workforce planning, the House of Commons Health and Social Care Committee has warned. ${ }^{1}$

However, there is a gap between ministers' statements and actions in terms of supporting frontline staff, the committee noted in a report into clearing the backlog. It described the government's decision to vote down a Health and Care Bill amendment that would have required annual public reports on workforce projections ${ }^{2}$ as a "refusal in practice to do the biggest single long-term change” to relieve pressure on staff.

MPs said in their report that without independent workforce projections it "remains impossible for anyone to know whether enough doctors, nurses or care staff are being trained," which represented a "significant accountability gap" and left staff not knowing when they could expect the pressure on them to lift.

The committee found it "totally unacceptable" that the budget for Health Education England, which funds training places for new doctors and nurses, remained unresolved, calling the lack of discussion around boosting training numbers "extremely disheartening.” Additional funding for Health Education England was notably missing from the government's recent autumn budget, which promised to tackle record high waiting lists. ${ }^{3}$

Jeremy Hunt, committee chair and former health secretary, said, "Our report finds that the government's recovery plans risk being thrown off course by an entirely predictable staffing crisis. The current wave of omicron is exacerbating the problem, but we already had a serious staffing crisis, with a burnt-out workforce, 93 ooo NHS vacancies and no sign of any plan to address this.

"Far from tackling the backlog, the NHS will be able to deliver little more than day-to-day firefighting unless the government wakes up to the scale of the staffing crisis facing the NHS and urgently develops a long term plan to fix the issue."

Commenting on the report, Anita Charlesworth, director of research at the Health Foundation, said, "A credible recovery strategy is desperately needed, and it needs to be backed up by sufficient funding and staff. To get back to the 18 week standard for waiting times across the NHS would require almost 19000 more nurses and over 4000 more doctors, but there is no staffing plan for the NHS."

\section{Emergency care}

The committee also warned that plans to deal with the record waiting list of 5.8 million for elective care risked being overturned by the current crisis in emergency care.
In October 2021, emergency department waiting times were the worst since records began, with one in four patients waiting longer than four hours to be admitted, transferred, or discharged, trolley waits at a record high, and the highest number of 999 calls on record.

"There is a serious risk that the ongoing crisis in emergency care could derail the elective recovery programme," the report warned.

\section{Social care}

Like Health Education England, social care was also largely overlooked in the autumn spending review, and the committee warned that without the right support for social care any recovery plan for the NHS would be "doomed to failure."

The report did credit the government with "grasping the nettle of social care reform" by publishing its white paper in December last year, ${ }^{4}$ but it said that this still did not acknowledge the scale of resources needed to ensure that the sector could recover from the current crisis. It added that commitments on areas such as workforce and unpaid carers were welcome but "did not go far enough."

The committee has called on the government to publish a 10 year plan for social care setting out in more detail how it will operationalise its ambitions, as well as a "people plan” for social care.

\section{Recommendations}

The committee's main recommendation is that the Department of Health and Social Care should now work with NHS England on a broader national health and care recovery plan by April 2022, going beyond the elective care backlog to deal with emergency care, mental health, primary care, community care, and social care.

It said that this plan must acknowledge that a reliance on numerical targets alone could risk patient safety and should set out a clear vision of what success will look like, as well as what patients could expect their care to look like in the next few years.

The committee has also repeated its previous recommendation that independently audited annual reports on workforce projections covering the next five, 10 , and 20 years should be published and should include an assessment of whether enough staff are being trained.

Correction: On 6 January 2022 we amended the title of this story from "Inaction on workforce planning has failed health and care staff, say MPs" to better reflect the story's main point about tackling the backlog.

House of Commons Health and Social Care Committee. Clearing the backlog caused by the pandemic. 6 Jan 2022. Available at: https://committees.parliament.uk/committee/81/health-and-social-care-committee/ 
2 Limb M. Workforce: health leaders lament lost chance to secure safe staffing in Health and Care Bill. BMJ 2021;375:n2900. doi: 10.1136/bmj.n2900 pmid: 34819314

3 Mahase E. NHS gets $\mathrm{f5} .9 \mathrm{bn}$ funding boost in autumn budget to tackle waiting lists in England. BMJ 2021;375:n2637. doi: 10.1136/bmj.n2637.

4 Wise J. Plans to reform adult social care fall short of promises, say critics. BMJ2021;375:n2980. doi: 10.1136/bmj.n2980 pmid: 34857540 